\title{
Early developmental pathways to autism spectrum disorder in tuberous sclerosis complex
}

\begin{tabular}{|r|l|}
\hline Journal: & Advances in Autism \\
\hline Manuscript ID & AIA-01-2016-0004.R1 \\
\hline Manuscript Type: & Review Paper \\
\hline Keywords: & $\begin{array}{l}\text { Autism Spectrum Disorder, Development, Infancy, Tuberous Sclerosis } \\
\text { Complex }\end{array}$ \\
\hline \multicolumn{2}{|l}{} \\
\hline
\end{tabular}

SCHOLARONE ${ }^{m}$

Manuscripts 


\title{
Early developmental pathways to autism spectrum disorder in tuberous sclerosis complex
}

\begin{abstract}
Tuberous sclerosis complex (TSC) is a genetic disorder with a high prevalence of autism spectrum disorder (ASD), yet no single genetic, neurological or neurophysiological risk marker is necessary or sufficient to increase risk for ASD. The increasing number of TSC infants presenting with abnormalities prenatally provides a unique opportunity to study risk pathways to ASD from birth. Here, we review findings to date that support the investigation of infants with TSC to further our understanding of typical and atypical development. Evidence has accumulated from studies of infants at familial risk for ASD ("baby siblings") to suggest that early markers of ASD are present in the first year of life. The early waves of prospective studies of infants with TSC indicate dynamic changes in developmental trajectories to ASD and are likely to provide insight into cascading effects of brain "insult" early in development. Emerging evidence of phenotypic and biological homology between syndromic and idiopathic cases of ASD supports the notion of a convergence of risk factors on a final common pathway in ASD. The delineation of brain-based biomarkers of risk, prediction and treatment response in TSC will be critical in aiding the development of targeted intervention and prevention strategies for those infants at high-risk of poorer developmental outcomes.
\end{abstract}

Key words: autism spectrum disorder, development, infancy, tuberous sclerosis complex 
Tuberous Sclerosis Complex (TSC) is a rare genetic disorder caused by a mutation on TSC1 on chromosome 9q34 or TSC2 on 16p13.3. TSC is characterised by the growth of benign lesions, called hamartomas, which grow throughout multiple organ systems. In addition to the primary mutation event, a series of second-hit mutations occur during embryogenesis which dysregulate the mechanistic target of rapamycin (mTOR) signaling pathway and ultimately lead to random variation in the location and number of hamartomas (Orlova and Crino, 2010). Hamartomas in the brain, or cortical tubers, and surrounding dysplastic tissue can act as epileptogenic foci, leading to electrophysiological disturbances from early in development. Epilepsy is present in 60-90\% of individuals with TSC and around two thirds of individuals with TSC and epilepsy have seizure onset in the first year of life (Chu - Shore et al., 2010). In addition to these clinical manifestations, children with TSC are at high risk of cognitive, behavioral and psychiatric disturbances, referred to as TSC Associated Neuropsychiatric Disorders (TAND; de Vries et al., 2015). For example, a large proportion of children with TSC will develop intellectual disability (ID; Prather and de Vries, 2004, de Vries et al., 2007, Joinson et al., 2003), and between 30-60\% of individuals with TSC meet criteria for autism spectrum disorder (ASD; Bolton, 2004, Jeste et al., 2008, Curatolo et al., 2004), all of which can co-occur in the same individual (de Vries et al., 2007), posing challenges for diagnosis. These associated neuropsychiatric manifestations have been identified as major determinants of morbidity and quality of life for individuals with TSC (de Vries, 2010, Orlova and Crino, 2010, Sparagana and Roach, 2000).

\section{Autism spectrum disorder in TSC}

TSC is one of the most commonly occurring single-gene disorders associated with ASD - the rate of TSC among individuals with ASD is estimated at 0.5-4\% (Fombonne, 2003, Kielinen et al., 2004, Richards et al., 2015). Conversely, rates of ASD in TSC approach 60\% (Jeste et al., 2008, Wong, 2006). Despite a common genetic aetiology, only a subset of individuals with TSC develop ASD, providing a valuable opportunity to study the developmental trajectories of these infants before onset of symptoms, with the goal of understanding causal pathways to the marked variability in outcome.

Of studies that have explored factors associated with a diagnosis of ASD in TSC, the majority have been small-scale, uncontrolled, retrospective investigations of clinic populations after an ASD diagnosis has been established (and hence, post-manifestation of cognitive and behavioral symptoms). These studies have revealed significant associations with ASD and the TSC2 mutation, cortical tuber burden and location in the temporal lobe and cerebellum, and the age at onset, severity and type of seizures, particularly a history of infantile spasms (Bolton et al., 2002, Numis et al., 2011). Moreover, several findings implicate aberrant connectivity as a key biomarker of behavioural outcome in TSC; the number of radial migration lines (white matter abnormalities) have been found to be associated with age at seizure onset, cognitive development and autistic features, and white matter alterations and loss of structural integrity are associated with the presence of ASD (Peters et al., 2012, Lewis et al., 2013, van 
Eeghen et al., 2013b). No single clinical feature, however, is predictive of ASD outcome. For example, there are children with TSC who develop ASD even without a history of seizures (Numis et al., 2011, Boronat et al., 2014). Moreover, while cortical tubers constitute one of the neurological abnormalities in TSC, preclinical research has suggested that altered neurotransmission, stemming from more subtle and widespread disturbances in brain structure and function (such as disturbances in axonal, dendritic and synaptic formation) exist independently of tubers (Goorden et al., 2007, Nie et al., 2010, Huang and Manning, 2008, Kwiatkowski, 2003). Thus developmental outcome is varied in TSC and the specific mechanisms that determine which individuals will, and will not, go on to develop ASD are yet to be clearly defined.

\section{A spotlight on infancy}

\section{Opportunities and challenges}

In TSC, the number of cases presenting with abnormalities identified at routine antenatal examination, such as positive screening of cardiac rhabdomyoma, has increased and now accounts for a substantial minority of cases (Yates et al., 2011), providing a unique opportunity to study risk pathways from birth in this population. The majority of previous work investigating the early years of TSC has relied on retrospective parental report, which is prone to various biases and problems with recall. For example, memory of videotaped events may be selective, and researchers are limited to the assessment of overt behaviours that have been captured on tape or are memorable to parents. Moreover, assessment tools that would typically be administered for infants with TSC, do not assess critical domains associated with cognitive development and are not sensitive to frequently repeated administrations, so are unable to capture sudden, rapid or fluctuating changes in development in relation to exposure to risk factors. In other disorders associated with infantile spasms, for example, there is some evidence suggesting that cognitive decline may be associated with additional factors, such as visual function, pre-existing cognitive/behavioural impairment and certain electroencephalographic (EEG) discharges (Chieffo et al., 2011, Brooks et al., 2002, Guzzetta, 2006, Watanabe et al., 1987). For example, interictal hypsarrhythmia, a frequent feature of spasms, is associated with poor developmental outcome, and studies of children with spasms have demonstrated a correlation between persistence of hypsarrhythmia and the emergence of ASD (Kayaalp et al., 2007, Spence and Schneider, 2009). In TSC, however, there is no specific information about the mechanisms underlying the variability in developmental outcome for infants with spasms and the brain mechanisms underlying developmental delays remain unknown. In addition, it is clear from previous research that the neurological features of TSC (e.g., tuber burden and location and seizure onset, type or severity) are not solely or entirely predictive of developmental outcomes. Most studies have focused on a single 'predictor' of outcome, yet it is likely that individual risk factors occurring at different stages in pre- and post-natal development cumulate risk for ASD in a cascading pathway (as indicated for ID, e.g. Bolton et al., 2015). The development of the brain in the first two years of life is very rapid and complex, and thus more vulnerable to exposure to risk factors. A priority therefore is to develop good quality measures that can be applied from birth in order to objectively study how early treatment can help individuals with TSC in the long-term. 


\section{Advances in Autism}

Prospective studies of ASD in infant siblings

Although studying TSC in the first two years is largely uncharted territory, there is now a wealth of data exploring the altered developmental trajectories of infant siblings at high familial risk for ASD. By comparing prospective data from infants who do or do not meet diagnostic criteria for ASD at 3 years of age, researchers can identify early markers of a later diagnosis. For example, several recent studies have revealed that infants at familial risk for ASD demonstrate atypical neural responses to social stimuli, altered visual orienting and deficits in disengaging attention (for recent extensive reviews, see Johnson et al., 2014, Jones et al., 2014, Gliga et al., 2014, Jeste et al., 2015). Importantly, studies of infants at risk for ASD outcome foster our understanding of the developmental trajectories and sequential impact of early delays or deviations in one domain on the subsequent development of other domains. For example, associations between early eye movements to social stimuli and later expressive language have been demonstrated (Elsabbagh et al., 2014), and social (gaze following) and non-social attention (attentional disengagement) appear to have independent and additive impacts on risk for ASD (Bedford et al., 2014).

Predictive markers of ASD in infancy do not, however, appear to cluster in a particular cognitive domain. It is unclear whether this reflects clinical and underlying genetic heterogeneity in ASD, which represent significant challenges to delineating the neurobiological risk processes involved (Geschwind and State, 2015, Jeste and Geschwind, 2014). By investigating a syndromic model system of ASD, such as TSC, the genetic cause can be constrained and the molecular pathway more tractable as the aetiology is known (Davis et al., 2015). Prospective studies of infants with TSC could therefore reveal the developmental origin of ASD.

\section{The examination of early developmental markers of risk for ASD in TSC}

The hierarchical, bottom-up, nature of brain development implies that early perturbations during basic circuit refinement may lead to widespread alterations in the development of 'low-level' functions (i.e., sensory and motor function) whereas later occurring impacts to the brain may contribute to more specific and localized disruptions in high-level domains, such as social orienting (Thompson and Levitt, 2010, Varcin and Nelson III, in press). The early 'insult' to the brain in TSC, occurring during embryogenesis, and onset of severe epileptic spasms in the first weeks or months of life, occur during a sensitive period of brain development (Johnson, 2001). On this basis, it can be hypothesized that widespread neural dysfunction is implicated. On the other hand, seizure onset later in development may independently impact higher-level brain functions. It is therefore crucial to objectively measure 'biomarkers' that index both low- and high-level domains of risk for ASD from very early in development in prospective longitudinal designs in order to better understand and predict the wide variability in outcome in TSC (Figure 1).

<FIGURE 1 HERE>

Prospective studies of infants with TSC 
Early studies of infants with infantile spasms show deterioration in cognitive ability after the onset of spasms and the later emergence of ASD and intractable epilepsy (Humphrey et al., 2014, Humphrey et al., 2006), yet are limited by sample size and a narrow range of assessments. A recent prospective, longitudinal study of infants with TSC aimed to map development over the first 3 years of life in TSC in order to characterize early developmental trajectories and identity potential predictors of ASD. Results from this study showed that infants with TSC manifest developmental delays by 6 months relative to typically developing infants (Jeste et al., 2014). At 6 months of age, developmental delays in TSC were specific to visually-mediated non-verbal skills, indexing the ability to process visual information and to coordinate small muscle movements, such as grip. By 9 months of age, infants with TSC were delayed across all domains of development (i.e., verbal, non-verbal and gross motor). By 12 months of age, infants who went on to meet criteria for ASD (as determined using the gold-standard Autism Diagnostic Observation Schedule [ADOS]; Lord et al.) had lower overall cognitive development compared to infants with TSC without ASD, suggesting differences between TSC with ASD and TSC without ASD are apparent by the first year of life. Between 12 and 36 months of age, infants with ASD showed a trajectory of cognitive development that was marked by a slowing in the attainment of visually-mediated, non-verbal skills compared to infants with TSC and no ASD. This developmental slowing through the non-verbal domain in TSC-ASD was apparent even after controlling for seizure severity. While a similar pattern of developmental slowing in non-verbal skills attainment has been reported in idiopathic ASD (e.g. Bishop et al., 2015, Landa et al., 2012), this is commonly accompanied by, or secondary to, prominent slowing in the verbal domain (e.g. Landa and Garrett-Mayer, 2006, Landa et al., 2012) (tanda and Garrett-Mayer, 2006), which suggests a potential domain-specific pathway of ASD risk in TSC. These findings highlight the importance of longitudinal assessments to examine dynamic changes in developmental trajectories in TSC.

(tanda et al., 2013)

\section{Integrating behavioral and brain measures in TSC}

Consistent with findings from older children with TSC showing associations between intellectual disability and ASD (Van Eeghen et al., 2013a), the results from this prospective study highlight the apparent inextricable link between cognitive development and ASD in TSC. On this basis, it has been suggested that cognitive impairment and social communicative deficits may stem from a common brain dysfunction in TSC (Van Eeghen et al., 2013a). Findings from animal models of rare genetic disorders, including TSC, suggest that alterations in synaptic function and structure may be a possible common mechanism for the emergence of both ASD and ID (Zoghbi and Bear, 2012). Recent advances in ASD genetics have demonstrated that many ASD risk genes converge on signaling pathways involved in protein synthesis, chromatic remodeling and synaptic structure and function - all processes related to neuronal transmission - suggestive of aberrant neural wiring through large-scale neural networks (De Rubeis et al., 2014). It is likely that sensitive and covert brain-based biomarkers (such as EEG, which serves as a measure of synaptic integrity at the large-scale network level) may therefore (1) provide a means of stratifying TSC populations according to risk for ASD (and ID), prior to the emergence of overt signs (Jeste et al., 2014, Varcin and Nelson III, in press) and (2) aid in diagnosis, prognosis and monitoring of treatment response. Importantly, non-invasive brain-based measures such 
as EEG, may be used from birth and can be used repeatedly across development, allowing for the mapping of developmental trajectories potentially prior, and subsequent, to seizure and/or treatment onset.

\section{Targeting a final common pathway}

The diverse range of genetic risk factors that have been implicated in ASD has led to speculation on whether the pathophysiological processes converge on a final common pathway or whether several subtypes of ASD exist, each with relatively distinct pathophysiological mechanisms and behavioural manifestations. If the latter were the case, different genetic causes of ASD would give rise to different phenotypic presentations, and alterations in more than one pathway may cumulate risk (Gliga et al., 2014). Conversely, a demonstration that the same biomarkers associated with idiopathic (no known cause) cases of ASD are shown in TSC will help to determine the extent to which the different behavioural outcomes map onto specific abnormalities in final common pathways.

\section{Phenotypic and biological convergence}

Despite the high prevalence rates, we know relatively little about the phenotypic characterization of ASD in children with TSC and if, and how, it differs from non-syndromic manifestations of ASD (Moss and Howlin, 2009, Van Eeghen et al., 2013a). A limited number of studies have now indicated some 'homology' between ASD in idiopathic and syndromic cases; abnormalities in event-related potential (ERP) indices of face processing differentiate adults with TSC without ASD and TSC with ASD, whereby the latter have exhibit longer N170 latencies and altered responses to face orientation, similar to adults with idiopathic ASD (Tye et al., 2015). Similar findings have been demonstrated in children with TSC and ASD (Jeste et al., 2013). In addition, application of machine learning algorithms to item scores on the Autism Diagnostic Interview-Revised (ADI-R) has revealed cases of idiopathic ASD exhibit similar behavioural phenotypes to cases with TSC (Bruining et al., 2014).

A study by Peters et al. (2013) analyzed EEG data using graph theory to model neural 'connectivity' in individuals with TSC with and without ASD and cases with 'idiopathic' ASD. TSC cases exhibited global under-connectivity and abnormal network topology, whereas individuals with TSC + ASD demonstrated similar connectivity patterns to those seen in individuals with idiopathic ASD: decreased long- over short-range connectivity (Peters et al., 2013). The similarity in connectivity abnormalities in TSC + ASD and ASD suggest a common final pathway and provide support for 'mis-wired' neural circuitry in ASD. The origins of the connectivity changes, and their role in mediating between the neural and the cognitive/behavioural manifestations, will require further study. Nevertheless, such system-level concepts may simplify and merge the diverse genetic mechanisms identified for ASD.

\section{Cross-disorder comparisons}

It will be important to map these brain-based abnormalities directly against those in infants at familial risk for ASD and with other genetic disorders (e.g. Fragile X, Neurofibromatosis) to allow identification of risk factors/absence of protective factors and to measure the generalisability of early predictive markers of ASD. Likewise, the high rates of 
co-occurrence of ASD with ID, as well as ADHD, in TSC, necessitates comparisons with other neurodevelopmental disorders in order to define trajectories that are linked to comorbid neuropsychiatric conditions. Implementing a protocol in TSC that is synergistic to batteries used in other "at-risk" groups will allow the identification of predictive markers of ASD outcome in TSC and provide a test of whether the same early predictive markers are present in TSC.

While it appears likely that in most cases there are multiple risk pathways to ASD, it is possible that these pathways converge at some level highlighting a means by which hundreds of genetic variants can lead to a common behavioural phenotype. The emerging behavioral and brain-based evidence for some homology between ASD in TSC and idiopathic ASD suggests that the various risk factors for ASD may operate in the same pathophysiological pathways that are up or down-regulated by the genetic syndrome. For example, the dysregulation of intracellular signaling through activation of the mTOR pathway could play a direct role in determining susceptibility to ASD, by altering the development of inhibitory synapses and synaptic plasticity (Ebert and Greenberg, 2013, Auerbach et al., 2011). It is, however, yet to be addressed whether additional genetic mutations occur in individuals with TSC and ASD that, independently of or interactively with the primary mutation, contribute to ASD risk. Further genetic investigation alongside brain-based biomarkers is likely to provide insight.

\section{The promise of biomarkers in TSC}

Identification of biomarkers of development will help to monitor the effects of new TSC treatments, and eventually to determine who will benefit from intervention. Prompt treatment with anti-epileptic medication in the first week of seizure onset may improve the long-term behavioural and cognitive function of children with TSC (Bombardieri et al., 2010, Cusmai et al., 2011). Changes in cognitive and brain development can occur weeks or months before seizure onset, which may facilitate preventative treatment in the advent of exciting new treatment approaches for TSC (Wu et al., 2016). Clinical trials are now underway directly testing the effect of mTOR inhibitors on autism symptoms (see summary in Davis et al., 2015), yet it is unclear whether this could lead to novel or improved treatments across a range of causes of ASD. Questions remain as to whether interventions initiated at the time of epilepsy affect the trajectory of cognitive development in TSC, and whether level of functioning prior to intervention affects efficacy, which holds numerous implications for patients and clinicians. In addition, it is important to note that targeting dysregulation in one pathway may potentially worsen outcomes in cases associated with abnormalities in other molecular pathways, as demonstrated in animal models of TSC and Fragile X syndrome (Auerbach et al., 2011). Behavioural interventions demonstrating efficacy in infants at familial risk for ASD (e.g. Green et al., 2015) may also hold promise for infants with TSC, given the proposed homology between idiopathic and syndromic cases. An early behavioral intervention pilot study, focused on supporting the development of non-verbal skills associated with social communication (Kasari et al., 2015) is currently underway in infants with TSC. Such early intervention programs will help to test the causal nature of developmental associations between low- and high-level brain functions.

\section{Conclusion}


The early waves of studies of infants with TSC have revealed some potential risk factors for ASD emerging in the first years of life. Several key themes have emerged for future work (see Box 1). Ongoing studies will cast light on the role of unique or multiple mechanisms leading to the emergence of ASD in TSC and more generally. Examining how variable developmental trajectories emerge from a dynamic interaction of risk factors during the period of maximal brain plasticity, paves the way for identification of a developmental window of opportunity for targeted early intervention to those at high-risk of ASD in TSC.

\section{References}

AUERBACH, B. D., OSTERWEIL, E. K. \& BEAR, M. F. 2011. Mutations causing syndromic autism define an axis of synaptic pathophysiology. Nature, 480, 63-68.

BEDFORD, R., PICKLES, A., GLIGA, T., ELSABBAGH, M., CHARMAN, T. \& JOHNSON, M. H. 2014. Additive effects of social and non- social attention during infancy relate to later autism spectrum disorder. Developmental Science.

BISHOP, S. L., FARMER, C. \& THURM, A. 2015. Measurement of nonverbal IQ in autism spectrum disorder: Scores in young adulthood compared to early childhood. Journal of autism and developmental disorders, 45, 966-974.

BOLTON, P. 2004. Neuroepileptic correlates of autistic symptomatology in tuberous sclerosis. Mental Retardation and Developmental Disabilities Research Reviews, 10, 126-131.

BOLTON, P., CLIFFORD, M., TYE, C., MACLEAN, C., HUMPHREY, A., LE MARECHAL, K., HIGGINS, J. N. P., NEVILLE, B. G., RIJSDIJK, F., YATES, J. R. \& CONSORTIUM, T. T. C. S. 2015. Intellectual Development in Tuberous Sclerosis Complex: Risk Factors \& Correlates in the Tuberous Sclerosis 2000 Cohort Study. Psychological Medicine, 45, 2321-2331.

BOLTON, P., PARK, R. J., HIGGINS, J. N. P., GRIFFITHS, P. D. \& PICKLES, A. 2002. Neuro-epileptic determinants of autism spectrum disorders in tuberous sclerosis complex. Brain, 125, 12471255.

BOMBARDIERI, R., PINCI, M., MOAVERO, R., CERMINARA, C. \& CURATOLO, P. 2010. Early control of seizures improves long-term outcome in children with tuberous sclerosis complex. European Journal of Paediatric Neurology, 14, 146-149.

BORONAT, S., SHAAYA, E., DOHERTY, C., CARUSO, P. \& THIELE, E. 2014. Tuberous sclerosis complex without tubers and subependymal nodules: a phenotype-genotype study. Clinical genetics, 86, 149-154.

BROOKS, B. P., SIMPSON, J. L., LEBER, S. M., ROBERTSON, P. L. \& ARCHER, S. M. 2002. Infantile spasms as a cause of acquired perinatal visual loss. Journal of American Association for Pediatric Ophthalmology and Strabismus, 6, 385-388.

BRUINING, H., EIJKEMANS, M., KAS, M., CURRAN, S. R., VORSTMAN, J. \& BOLTON, P. F. 2014. Behavioral signatures related to genetic disorders in autism. Mol Autism, 5.

CHIEFFO, D., RICCI, D., BARANELLO, G., MARTINELLI, D., VEREDICE, C., LETTORI, D., BATTAGLIA, D., DRAVET, C., MERCURI, E. \& GUZZETTA, F. 2011. Early development in Dravet syndrome; visual function impairment precedes cognitive decline. Epilepsy research, 93, 73-79.

CHU - SHORE, C. J., MAJOR, P., CAMPOSANO, S., MUZYKEWICZ, D. \& THIELE, E. A. 2010. The natural history of epilepsy in tuberous sclerosis complex. Epilepsia, 51, 1236-1241.

CURATOLO, P., PORFIRIO, M. C., MANZI, B. \& SERI, S. 2004. Autism in tuberous sclerosis. European Journal of Paediatric Neurology, 8, 327-332.

CUSMAI, R., MOAVERO, R., BOMBARDIERI, R., VIGEVANO, F. \& CURATOLO, P. 2011. Long-term neurological outcome in children with early-onset epilepsy associated with tuberous sclerosis. Epilepsy \& Behavior, 22, 735-739. 
DAVIS, P. E., PETERS, J. M., KRUEGER, D. A. \& SAHIN, M. 2015. Tuberous Sclerosis: A New Frontier in Targeted Treatment of Autism. Neurotherapeutics, 12, 572-583.

DE RUBEIS, S., HE, X., GOLDBERG, A. P., POULTNEY, C. S., SAMOCHA, K., CICEK, A. E., KOU, Y., LIU, L., FROMER, M. \& WALKER, S. 2014. Synaptic, transcriptional and chromatin genes disrupted in autism. Nature, 515, 209-215.

DE VRIES, P. 2010. Neurodevelopmental, psychiatric and cognitive aspects of tuberous sclerosis complex. Tuberous Sclerosis Complex: Genes, Clinical Features and Therapeutics, 229-267.

DE VRIES, P., HUNT, A. \& BOLTON, P. F. 2007. The psychopathologies of children and adolescents with tuberous sclerosis complex (TSC): a postal survey of UK families. European Child \& Adolescent Psychiatry, 16, 16-24.

DE VRIES, P., WHITTEMORE, V. H., LECLEZIO, L., BYARS, A. W., DUNN, D., ESS, K. C., HOOK, D., KING, B. H., SAHIN, M. \& JANSEN, A. 2015. Tuberous sclerosis associated neuropsychiatric disorders (TAND) and the TAND Checklist. Pediatric neurology, 52, 25-35.

EBERT, D. H. \& GREENBERG, M. E. 2013. Activity-dependent neuronal signalling and autism spectrum disorder. Nature, 493, 327-337.

ELSABBAGH, M., BEDFORD, R., SENJU, A., CHARMAN, T., PICKLES, A., JOHNSON, M. H. \& TEAM, B. 2014. What you see is what you get: contextual modulation of face scanning in typical and atypical development. Social cognitive and affective neuroscience, 9, 538-543.

FOMBONNE, E. 2003. Epidemiological surveys of autism and other pervasive developmental disorders: an update. Journal of autism and developmental disorders, 33, 365-382.

GESCHWIND, D. H. \& STATE, M. W. 2015. Gene hunting in autism spectrum disorder: on the path to precision medicine. The Lancet Neurology.

GLIGA, T., JONES, E. J. H., BEDFORD, R., CHARMAN, T. \& JOHNSON, M. H. 2014. From early markers to neuro-developmental mechanisms of autism. Developmental Review, 34, 189-207.

GOORDEN, S. M., VAN WOERDEN, G. M., VAN DER WEERD, L., CHEADLE, J. P. \& ELGERSMA, Y. 2007. Cognitive deficits in Tsc1+/ầ mice in the absence of cerebral lesions and seizures. Annals of neurology, 62, 648-655.

GREEN, J., CHARMAN, T., PICKLES, A., WAN, M. W., ELSABBAGH, M., SLONIMS, V., TAYLOR, C., MCNALLY, J., BOOTH, R. \& GLIGA, T. 2015. Parent-mediated intervention versus no intervention for infants at high risk of autism: a parallel, single-blind, randomised trial. The Lancet Psychiatry, 2, 133-140.

GUZZETTA, F. 2006. Cognitive and Behavioral Outcome in West Syndrome. Epilepsia, 47, 49-52.

HUANG, J. \& MANNING, B. D. 2008. The TSC1-TSC2 complex: a molecular switchboard controlling cell growth. The Biochemical journal, 412, 179.

HUMPHREY, A., MACLEAN, C., PLOUBIDIS, G. B., GRANADER, Y., CLIFFORD, M., HASLOP, M., NEVILLE, B. G., YATES, J. R., BOLTON, P. \& GROUP, T. S. S. 2014. Intellectual development before and after the onset of infantile spasms: a controlled prospective longitudinal study in tuberous sclerosis. Epilepsia, 55, 108-116.

HUMPHREY, A., NEVILLE, B. G., CLARKE, A. \& BOLTON, P. F. 2006. Autistic regression associated with seizure onset in an infant with tuberous sclerosis. Developmental Medicine \& Child Neurology, 48, 609-611.

JESTE, S. S., FROHLICH, J. \& LOO, S. K. 2015. Electrophysiological biomarkers of diagnosis and outcome in neurodevelopmental disorders. Current opinion in neurology, 28, 110-116.

JESTE, S. S. \& GESCHWIND, D. H. 2014. Disentangling the heterogeneity of autism spectrum disorder through genetic findings. Nature Reviews Neurology, 10, 74-81.

JESTE, S. S., HIRSCH, S., VOGEL-FARLEY, V., NORONA, A., NAVALTA, M.-C., GREGAS, M. C., PRABHU, S. P., SAHIN, M. \& NELSON, C. A. 2013. Atypical Face Processing in Children With Tuberous Sclerosis Complex. Journal of Child Neurology, 28, 1569-1576.

JESTE, S. S., SAHIN, M., BOLTON, P., PLOUBIDIS, G. B. \& HUMPHREY, A. 2008. Characterization of autism in young children with tuberous sclerosis complex. Journal of child neurology, 23, 520525. 
JESTE, S. S., WU, J. Y., SENTURK, D., VARCIN, K., KO, J., MCCARTHY, B., SHIMIZU, C., DIES, K., VOGELFARLEY, V. \& SAHIN, M. 2014. Early developmental trajectories associated with ASD in infants with tuberous sclerosis complex. Neurology, 83, 160-168.

JOHNSON, M. H. 2001. Functional brain development in humans. Nature Reviews Neuroscience, 2, $475-$ 483.

JOHNSON, M. H., GLIGA, T., JONES, E. \& CHARMAN, T. 2014. Annual Research Review: Infant development, autism, and ADHD - early pathways to emerging disorders. Journal of Child Psychology and Psychiatry, n/a-n/a.

JOINSON, C., O'CALLAGHAN, F., OSBORNE, J., MARTYN, C., HARRIS, T. \& BOLTON, P. 2003. Learning disability and epilepsy in an epidemiological sample of individuals with tuberous sclerosis complex. Psychological Medicine, 33, 335-344.

JONES, E. J., GLIGA, T., BEDFORD, R., CHARMAN, T. \& JOHNSON, M. H. 2014. Developmental pathways to autism: A review of prospective studies of infants at risk. Neuroscience \& Biobehavioral Reviews, 39, 1-33.

KASARI, C., GULSRUD, A., PAPARELLA, T., HELLEMANN, G. \& BERRY, K. 2015. Randomized comparative efficacy study of parent-mediated interventions for toddlers with autism. Journal of consulting and clinical psychology, 83, 554.

KAYAALP, L., DERVENT, A., SALTIK, S., ULUDUZ, D., KAYAALP, I. V., DEMIRBILEK, V. \& GHAZIUDDIN, M. 2007. EEG abnormalities in West syndrome: correlation with the emergence of autistic features. Brain and Development, 29, 336-345.

KIELINEN, M., RANTALA, H., TIMONEN, E., LINNA, S.-L. \& MOILANEN, I. 2004. Associated medical disorders and disabilities in children with autistic disorder a population-based study. Autism, 8, 49-60.

KWIATKOWSKI, D. 2003. Tuberous sclerosis: from tubers to mTOR. Annals of human genetics, 67, 8796.

LANDA, R. \& GARRETT-MAYER, E. 2006. Development in infants with autism spectrum disorders: a prospective study. Journal of Child Psychology and Psychiatry, 47, 629-638.

LANDA, R. J., GROSS, A. L., STUART, E. A. \& BAUMAN, M. 2012. Latent class analysis of early developmental trajectory in baby siblings of children with autism. Journal of Child Psychology and Psychiatry, 53, 986-996.

LANDA, R. J., GROSS, A. L., STUART, E. A. \& FAHERTY, A. 2013. Developmental trajectories in children with and without autism spectrum disorders: the first 3 years. Child development, 84, 429-442.

LEWIS, W. W., SAHIN, M., SCHERRER, B., PETERS, J. M., SUAREZ, R. O., VOGEL-FARLEY, V. K., JESTE, S. S., GREGAS, M. C., PRABHU, S. P. \& NELSON, C. A. 2013. Impaired language pathways in tuberous sclerosis complex patients with autism spectrum disorders. Cerebral Cortex, 23, 1526-1532.

MOSS, J. \& HOWLIN, P. 2009. Autism spectrum disorders in genetic syndromes: implications for diagnosis, intervention and understanding the wider autism spectrum disorder population. Journal of Intellectual Disability Research, 53, 852-873.

NIE, D., DI NARDO, A., HAN, J. M., BAHARANYI, H., KRAMVIS, I., HUYNH, T., DABORA, S., CODELUPPI, S., PANDOLFI, P. P. \& PASQUALE, E. B. 2010. Tsc2-Rheb signaling regulates EphA-mediated axon guidance. Nature Neuroscience, 13, 163-172.

NUMIS, A., MAJOR, P., MONTENEGRO, M., MUZYKEWICZ, D., PULSIFER, M. \& THIELE, E. 2011. Identification of risk factors for autism spectrum disorders in tuberous sclerosis complex. Neurology, 76, 981-987.

ORLOVA, K. A. \& CRINO, P. B. 2010. The tuberous sclerosis complex. Annals of the New York Academy of Sciences, 1184, 87-105.

PETERS, J., TAQUET, M., VEGA, C., JESTE, S., FERNÁNDEZ, I. S., TAN, J., NELSON, C., III, SAHIN, M. \& WARFIELD, S. 2013. Brain functional networks in syndromic and non-syndromic autism: a graph theoretical study of EEG connectivity. BMC Medicine C7 - 54, 11, 1-16.

PETERS, J. M., SAHIN, M., VOGEL-FARLEY, V. K., JESTE, S. S., NELSON, C. A., GREGAS, M. C., PRABHU, S. P., SCHERRER, B. \& WARFIELD, S. K. 2012. Loss of white matter microstructural integrity is 
associated with adverse neurological outcome in tuberous sclerosis complex. Academic radiology, 19, 17-25.

PRATHER, P. \& DE VRIES, P. 2004. Behavioral and cognitive aspects of tuberous sclerosis complex. Journal of child neurology, 19, 666-674.

RICHARDS, C., JONES, C., GROVES, L., MOSS, J. \& OLIVER, C. 2015. Prevalence of autism spectrum disorder phenomenology in genetic disorders: a systematic review and meta-analysis. The Lancet Psychiatry, 2, 909-916.

SPARAGANA, S. P. \& ROACH, E. S. 2000. Tuberous sclerosis complex. Current opinion in neurology, 13, 115-119.

SPENCE, S. J. \& SCHNEIDER, M. T. 2009. The role of epilepsy and epileptiform EEGs in autism spectrum disorders. Pediatric Research, 65, 599-606.

THOMPSON, B. L. \& LEVITT, P. 2010. The clinical-basic interface in defining pathogenesis in disorders of neurodevelopmental origin. Neuron, 67, 702-712.

TYE, C., FARRONI, T., VOLEIN, A., MERCURE, E., TUCKER, L., JOHNSON, M. \& BOLTON, P. 2015. Autism diagnosis differentiates neurophysiological responses to faces in adults with tuberous sclerosis complex. Journal of Neurodevelopmental Disorders, 7, 33.

VAN EEGHEN, A. M., PULSIFER, M. B., MERKER, V. L., NEUMEYER, A. M., VAN EEGHEN, E. E., THIBERT, R. L., COLE, A. J., LEIGH, F. A., PLOTKIN, S. R. \& THIELE, E. A. 2013a. Understanding relationships between autism, intelligence, and epilepsy: a cross - disorder approach. Developmental Medicine \& Child Neurology, 55, 146-153.

VAN EEGHEN, A. M., TERÁN, L. O., JOHNSON, J., PULSIFER, M. B., THIELE, E. A. \& CARUSO, P. 2013b. The neuroanatomical phenotype of tuberous sclerosis complex: focus on radial migration lines. Neuroradiology, 1-8.

VARCIN, K. \& NELSON III, C. A. in press. A developmental neuroscience approach to the search for biomarkers in autism spectrum disorder. Current opinion in neurology.

WATANABE, K., TAKEUCHI, T., HAKAMADA, S. \& HAYAKAWA, F. 1987. Neurophysiological and neuroradiological features preceding infantile spasms. Brain and Development, 9, 391-398.

WONG, V. 2006. Study of the relationship between tuberous sclerosis complex and autistic disorder. Journal of child neurology, 21, 199-204.

WU, J. Y., PETERS, J. M., GOYAL, M., KRUEGER, D., SAHIN, M., NORTHRUP, H., AU, K. S., CUTTER, G. \& BEBIN, E. M. 2016. Clinical Electroencephalographic Biomarker for Impending Epilepsy in Asymptomatic Tuberous Sclerosis Complex Infants. Pediatric neurology, 54, 29-34.

YATES, J. R., MACLEAN, C., HIGGINS, J. N. P., HUMPHREY, A., LE MARECHAL, K., CLIFFORD, M., CARCANI-RATHWELL, I., SAMPSON, J. R. \& BOLTON, P. F. 2011. The Tuberous Sclerosis 2000 Study: presentation, initial assessments and implications for diagnosis and management. Archives of disease in childhood, 96, 1020-1025.

ZOGHBI, H. Y. \& BEAR, M. F. 2012. Synaptic dysfunction in neurodevelopmental disorders associated with autism and intellectual disabilities. Cold Spring Harbor perspectives in biology, 4, a009886. 
Box 1: Outstanding questions

- Is it possible to disentangle longitudinal associations between low-level and more complex cognitive and neural mechanisms from birth?

- Can early intervention or prevention strategies be developed that target infants with TSC who are likely to develop ASD, and test the causal nature of developmental associations?

- Are there distinct developmental trajectories linked to comorbidity between ASD, ID and ADHD in TSC?

- Is there a homology in biomarkers between infants at familial risk for ASD and infants with genetic disorders with a high incidence of ASD?

- Are there protective mechanisms or canalisation in individuals with a very mild phenotype? 


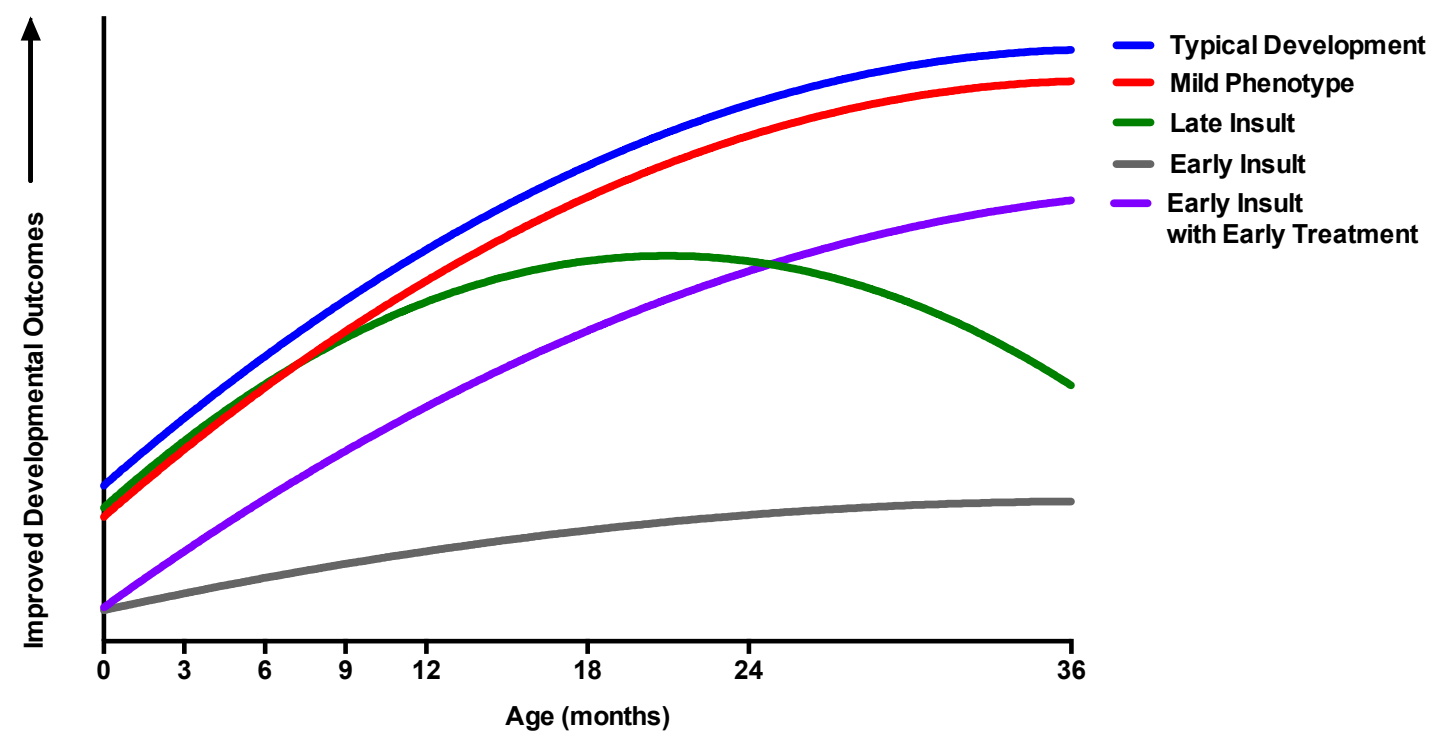

Figure 1. Hypothetical early developmental trajectories in TSC 